\title{
Rheological Properties of Polyolefin Blends Containing Long-Chain Branched Polypropylene as Dispersed Phase
}

\author{
Masayuki Yamaguchi ${ }^{*}{ }^{\dagger}$, Yoko FujII ${ }^{*}$, and Panitha Phulkerd ${ }^{*}$ \\ "School of Materials Science, Japan Advanced Institute of Science and Technology, 1-1 Asahidai, Nomi, Ishikawa 923-1292, Japan
}

\begin{abstract}
Rheological properties for binary polyolefin blends composed of linear low-density polyethylene (LLDPE) and longchain branched polypropylene (LCB-PP), in which LCB-PP is the dispersed phase, were studied. Even though LCB-PP was in the dispersed phase, the blend showed marked strain-hardening behavior in the transient elongational viscosity. The deformed LCB-PP droplets acted as "rigid fibers" during the elongational flow owing to its strain-hardening behavior. Consequently, the blend behaved like a fiber-dispersion system and thus exhibited the enhanced elongational viscosity, originated from excess deformation of LLDPE located between fibrous LCB-PP droplets under the elongational flow. Under shear flow, the primary normal stress difference was not enhanced by the addition of LCB-PP. This is reasonable because LCB-PP droplets oriented to the flow direction did not provide excess deformation of a continuous phase greatly.

Key Words: Polyolefin blend / Elongational viscosity / Long-chain branch
\end{abstract}

\section{長鎖分岐ポリプロピレンを分散相とする ポリオレフィンブレンドのレオロジー特性}

山口 政之*, , 藤井 陽子*, プルカードパニター*

(原稿受理 : 2019 年 12 月 15 日)

\section{1. 緒 言}

高分子溶融体の伸長粘度を制御しようとする研究は, 成形 加工性向上の観点から重要である ${ }^{1-3)}$. 伸長粘度がひずみとと もに急激に増加する「ひずみ硬化性」を示す材料は, ブロー 成形や熱成形における偏肉を抑制し， $\mathrm{T}$ ダイ成形における ネックインを抑制するとともにドローレゾナンスを生じにく くし，さらに，インフレーションフィルム成形におけるバブ ルの安定性を高める。また，ブロー成形や熱成形時の熱垂れ 抑制や発泡成形における破泡の抑制などにも効果的であるこ とが知られている ${ }^{3-5)}$. 最近ではシシカバブ構造の形成に重要 な役割を果たすことも明らかになりつつあり ${ }^{6}$, 成形加工性 のみならず固体構造や力学特性の制御にも有効であると認め られている。

我々は，これまでに臨界点近傍のゲルや，柔軟なナノファ イバーをごく少量添加することで, 伸長粘度のひずみ硬化性 が顕在化することを明らかにしている7-12). なお，一般的に は，超高分子量成分や長鎖分岐鎖の導入が伸長粘度のひずみ 硬化発現に効果的であることが認識されており ${ }^{2-5,13-15)}$, 工業 的な材料設計にもすでに取り込まれている. 長鎖分岐高分子 をこれと相溶する直鎖高分子にブレンドする手法もその一つ

\footnotetext{
†北陸先端科学技術大学院大学マテリアルサイエンス系

干923-1292 石川県能美市旭台1-1

E-mail : m_yama@jaist.ac.jp, Tel : 0761-51-1621
}

とみなすことができる5 ，その代表例である直鎖状低密度ポ リエチレン（LLDPE）に低密度ポリエチレン（LDPE）をブ レンドする手法は, 成形加工性を高めるための常套手段とし て用いられている ${ }^{16,17)}$ 。 なお, LDPE は高圧下ラジカル重合 で製造されており，分子中に長鎖分岐が存在している.

直鎖状のポリプロピレン（PP）にこれとは非相溶である LDPE をブレンドする手法も, 成形加工性向上を目的として しばしば行われている。この場合, ブレンドは相分離構造を 形成する. LDPE は分散相として存在し, 連続相である PP 中には長鎖分岐が存在しないのであるが, ブレンドはひずみ 硬化を示す ${ }^{18-20)}$ ．これはLDPE 分散相が急激に硬化すること が原因であると考えられている ${ }^{19,20)}$ 。すなわち, LDPEの粘 度が低い場合, 伸長流動場において分散相であるLDPE は連 続相であるPP とともにアフィン的に変形する。ところがあ る程度伸長すると, ひずみ硬化性のため引き伸ばされた LDPE 分散相が急激に「硬く」なる。その結果, 系全体が剛 直繊維分散系のように振る舞うことになる。剛直繊維分散系 の伸長粘度は, 以下の式で表される ${ }^{21)}$.

$$
\eta_{E}=\eta_{0}\left[3+\frac{4 \phi(l / d)^{2}}{3 \ln (\pi / \phi)}\right]
$$

$l / d$ は繊維のアスペクト比， $\eta_{0}$ は連続相のゼロせん断粘度， $\phi$ は繊維の体積分率である。この式は定常状態における伸長粘 度を表しており，実験的にも妥当性は証明されている ${ }^{22}$. 伸 長流動場では繊維間に存在する連続相が過剩な变形を受ける 
ため高い伸長粘度を示すのであるが，Laun はその挙動をわ かりやすく説明している ${ }^{23)}$. なお, 剛直繊維分散系は伸長粘 度が線形粘弾性で予測されるよりも高い值を示すが，ひずみ 硬化性が顕在化するわけではない。むしろ，ひずみ硬化は抑 制される ${ }^{24)}$ ，ただし，PP/LDPE ブレンドの場合には，変形が 進んで急激にLDPE 分散相が剛直な繊維状フィラーとして作 用することになる。そのため, 流動開始直後の伸長粘度は高 くなく、ひずみとともに急激に増加する。その結果, 実質的 にひずみ硬化性を示す。さて，もし上述のメカニズムが正し ければ，PP/LDPE ブレンドに限らず，直鎖高分子中に長鎖 分岐高分子が分散した溶融体では同様の挙動が観測されるは ずである。しかしながら, 著者の知る限り, そのような報告 はこれまでに行われていない。また，剛直繊維分散系では， 繊維が流動方向に配向するとせん断場での粘度上昇はわずか となり, 第一法線応力差も増加しない ${ }^{23)}$. しかしながら, PP/LDPE 系の法線応力差に関してはこれまで実験例が報告 されていない，そこで，本研究では，直鎖状高分子である LLDPE に長鎖分岐が存在するポリプロピレンを分散相とし てブレンドし，そのレオロジー特性を伸長およびせん断流動 場で調べた。

\section{2. 実 験}

市販の直鎖状低密度ポリエチレン（LLDPE）と長鎖分岐 ポリプロピレン（LCB-PP）を用いた。 LLDPE はメタロセン 触媒により製造されたエチレン・へキセン共重合体（プライ ムポリマー, エボリュー SP1510) であり, $190{ }^{\circ} \mathrm{C}, 2.16 \mathrm{~kg}$ 荷重に抄けるメルトフローレート（MFR）は $1.0 \mathrm{~g} / 10 \mathrm{~min}$,

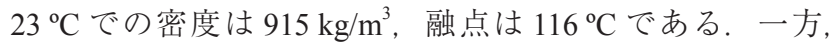
LCB-PP（Basell, Pro-Fax PF-814）の MFR は $230{ }^{\circ} \mathrm{C}, 2.16 \mathrm{~kg}$ 荷重において $3.0 \mathrm{~g} / 10 \mathrm{~min}$ である. なお, 本実験で用いた LCB-PP の希薄溶液物性および溶融粘弾性については, すで にその詳細を報告済みである25).

LLDPE と LCB-PP 70/30の重量比で密閉式混練機（東

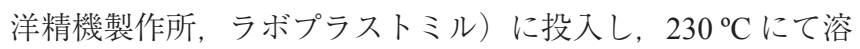
融混合を行った。混練時間は 10 分, ブレード回転数は

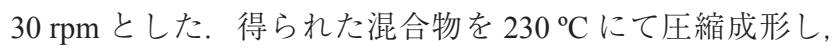

フィルム形状にした。

動的せん断弾性率，定常流特性の測定は円錐 - 円板レオ メータ（TAインスッルメンツ, AR2000eX) で行った。 コーン角は $4^{\mathrm{o}}$, 直径は $25 \mathrm{~mm}$ である, 伸長粘度の時間成長 曲線は SER 法 (Sentmanat Extensional Rheometer) により 行った。試料厚みは $0.8 \mathrm{~mm}$, 幅は $10 \mathrm{~mm}$ とした。

ブレンドの相構造は走査型電子顕微鏡 SEM（日立ハイテ クノロジーズ，S4100）で観察した。液体窒素中で破断した サンプル表面をPt-Pd 蒸着して測定に用いた.

\section{3. 結果と考察}

LLDPE と LCB-PP の動的せん断弾性率の角速度依存性を Fig. 1 に示す. LLDPE は緩和時間分布が狭く, LCB-PP は緩 和時間分布が広いことがわかる. 角速度 $10^{-1} \mathrm{~s}^{-1}$ 以上の領域 では LLDPEの方が高い損失弾性率を示す。なお, メ夕ロセ ン触媒で製造された LLDPE は分子量分布が狭いことが知ら れており，また，LCB-PPは電子線や過酸化物架橋により長
鎖分岐が導入されているため緩和時間分布はかなりブロード になることが報告されている ${ }^{4,25)}$.

ブレンドの動的せん断弾性率を Fig. 2 に示す.PP と LLDPEの相溶性については古くから調べられている。それ によると, PP と市販の LLDPE は非相溶である。ただし, LLDPE 中の短鎖分岐数が増加するにしたがって界面張力は 低くなり， $\alpha$-オレフィンの共重合量がエチレンを上回るよ うになると熱力学的に相溶する ${ }^{26-28)}$. 本実験で用いた LLDPE の分岐数は十分に少なく PP とは非相溶である。ブレンドの 動的粘弾性では，長時間領域に相分離に基づく緩和機構が観 測されており，また，図中に示したSEM写真からも直径 $1 \mu \mathrm{m}$ 程度の分散粒子が観測されている。

本試料を用いて伸長粘度成長曲線を測定した。Fig. 3 に結 果を示す。図中の実線は, 動的せん断弾性率から以下の式 ${ }^{29)}$ より求めた線形領域のせん断粘度成長曲線の三倍の值である.

$$
\eta^{+}(t)=\left.t\left[G^{\prime \prime}(\omega)+1.12 G^{\prime}(\omega / 2)-0.200 G^{\prime}(\omega)\right]\right|_{\omega=1 / t}
$$

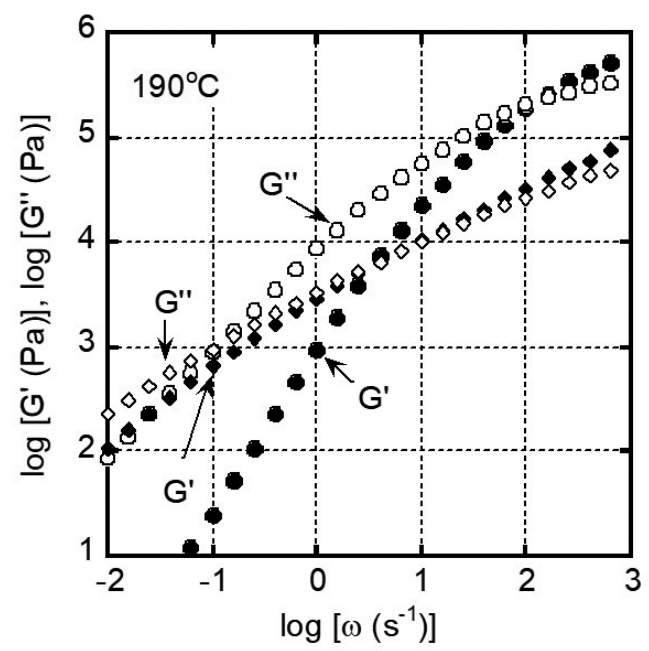

Fig. 1 Angular frequency dependence of (closed symbols) shear storage modulus $G^{\prime}$ and (open symbols) loss modulus $G^{\prime \prime}$ at $190^{\circ} \mathrm{C}$ for (circles) LLDPE and (diamonds) LCB-PP.

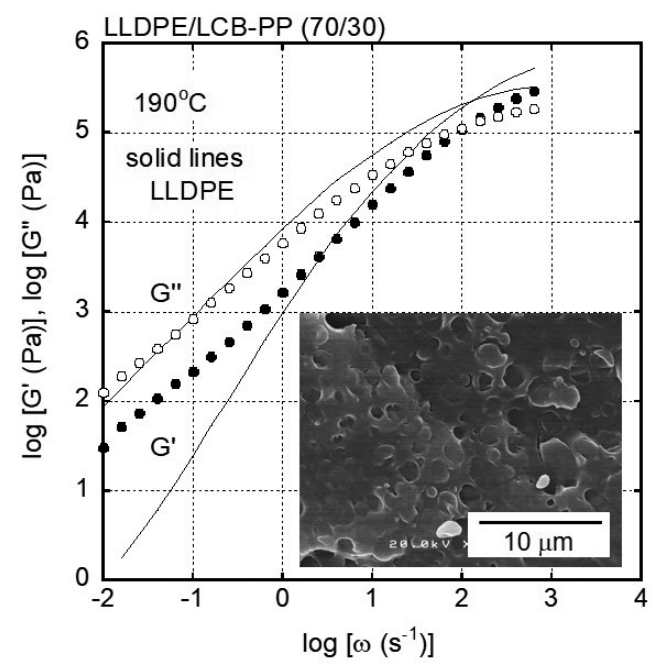

Fig. 2 Angular frequency dependence of (closed circles) shear storage modulus $G^{\prime}$ and (open circles) loss modulus $G^{\prime \prime}$ at $190{ }^{\circ} \mathrm{C}$ for LLDPE/LCBPP (70/30). The solid lines represent the data of pure LLDPE. The SEM image of the fractured surface of the blend is shown in the figure. 

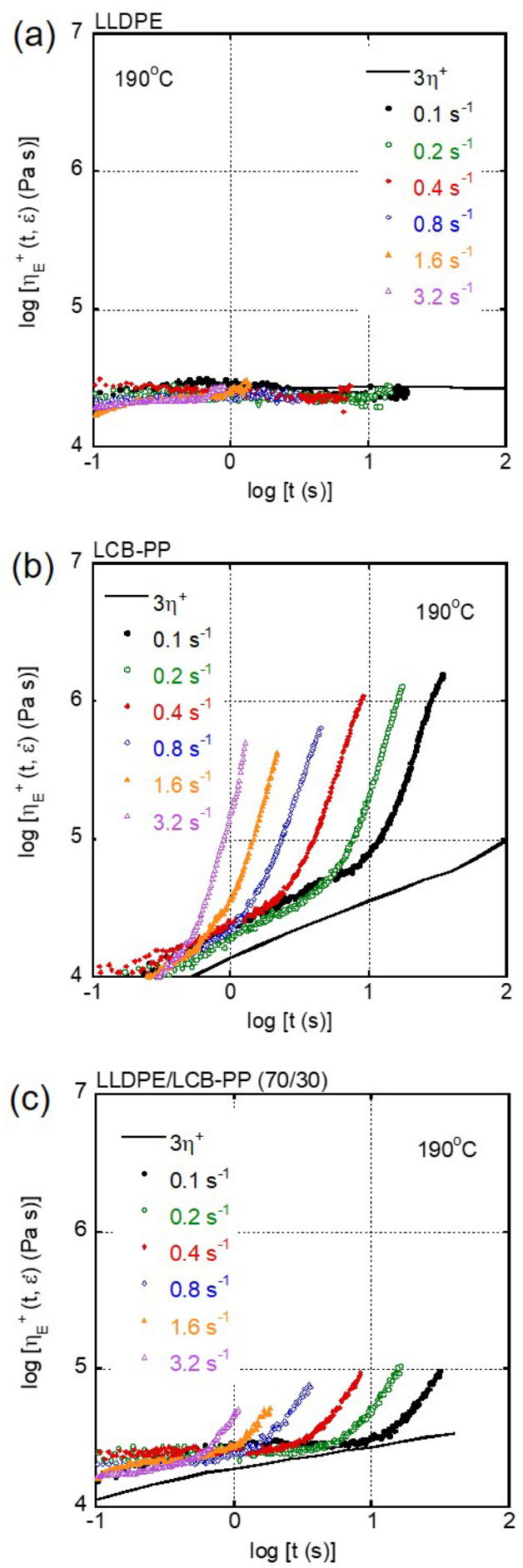

(d)

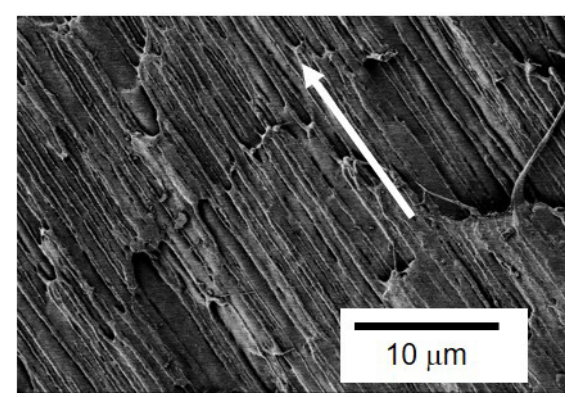

Fig. 3 Growth curves of uniaxial elongational viscosity at various strain rates at $190^{\circ} \mathrm{C}$ for (a) LLDPE, (b) LCB-PP, and (c) LLDPE/LCB-PP (70/30). The SEM picture of the fractured surface of the blend sample stretched for $6 \mathrm{~s}$ at $0.4 \mathrm{~s}^{-1}$ is also shown in (d), in which the arrow represents the stretching direction.
よく知られているように，長鎖分岐の存在しない LLDPE はひずみ硬化を生じず，LCB-PP は顕著なひずみ硬化性を示 す。これらの挙動は本実験でも確認された。また, LLDPE と LCB-PP を比較した場合, 短時間すなわちひずみが小さい 領域では LLDPEの方が高い伸長粘度を示すことがわかる。

連続相が LLDPE で分散相が LCB-PP となっているブレン ドにおいても，測定したすべてのひずみ速度でひずみ硬化性 を示すことが判明した。すすおち，分散相がひずみ硬化性を 示す溶融体で構成された相分離系ブレンドでは，伸長粘度成 長曲線にひずみ硬化が観測されるといえる。

Fig. 3 (d) はひずみ速度 $0.4 \mathrm{~s}^{-1}$ で伸長し，6秒後に延伸停止 して急冷した LLDPE/LCB-PP（70/30）の冷凍破断面の SEM 写真である. LCB-PP 分散相が流れ方向に強く配向している ことがわかる. 以上の結果より, 延伸開始直後は連続相とと もに分散相はアフィン的な変形を生じ繊維形状になる $(\text { Fig. } 4)^{20)}$. ある程度, 変形が進むと LCB-PP 自身のひずみ硬 化性により「硬く」なる，硬くなった後の状況は剛直䋊維分 散系とよく似ている。剛直繊維が分散した系ではひずみ硬化 は顕在化しないものの, 伸長粘度が線形領域よりも大きな值 を示す $(1 \text { 式 })^{21)}$. これは伸長とともに隣接繊維間の距離が 短くなり, 䋊維間に存在する連続相に大きな変形が生じるこ とに起因する ${ }^{22,23)}$.

伸長粘度の測定は温度を一定に保って行っているが, 非等 温下では同様の現象がすでに報告されている。例えば，直鎖 状 PP にPP と非相溶な低分子量アクリル樹脂を少量混合し た場合, PP の融点以上の温度ではアクリル樹脂は低粘度で あり伸長流動場において連続相であるPPとともに変形し繊 維形状の分散相となる。 その後, 急激に冷却されるとPP の 結晶化前にアクリル樹脂のガラス化が生じ，アクリル樹脂が 剛直繊維として振る舞うことになる。 その結果, 非等温下で の溶融延伸に必要な力は著しく大きくなる ${ }^{30)}$.

一方，剛直繊維分散系にせん断流動を与えて繊維が流動方 向に配向すると, せん断粘度の大幅な増加は観測されないこ とが知られている ${ }^{23,24)}$. この場合, 第一法線応力差も大きく 増加することはなく繊維が剛体であれば法線応力差はむしろ 低下する。

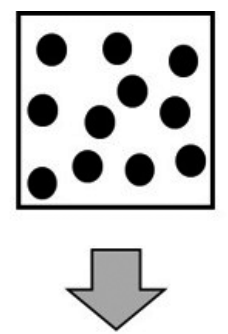

Droplets deform into fibrous shape.

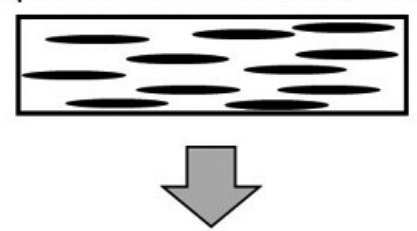

Droplets behave like rigid fibers.

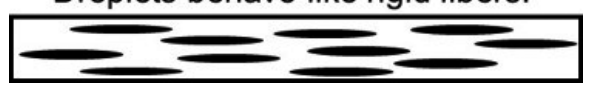

Fig. 4 Schematic illustration of structure development for dispersed LCB-PP droplets in the LLDPE matrix under uniaxial elongational flow. 


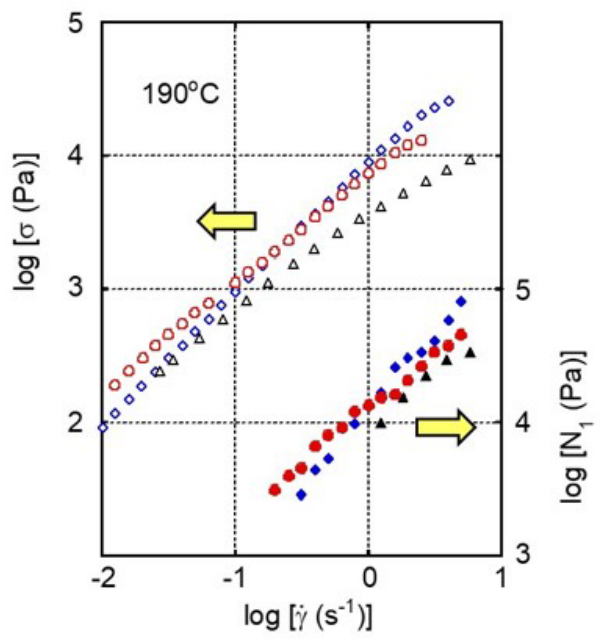

Fig. 5 Steady-state shear stress $\sigma$ and primary normal stress difference $N_{1}$ as a function of shear rate $\dot{\gamma}$ at $190{ }^{\circ} \mathrm{C}$.

(circles) LLDPE/LCB-PP (70/30), (diamonds) LLDPE, and (triangles) LCB-PP.

そこで本系においても定常状態におけるせん断流動特性を 評価した。 Fig. 5 に示す通り, LCB-PPを混合すると LLDPE とほぼ同じ程度の第一法線応力差を示す。また, 高せん断速 度域ではやや低い值を示す。せん断応力もほぼ同様の挙動を 示す。

なお, LLDPEへの LDPEの混合や，直鎖状 PPへの LCBPP の混合など，相溶系ブレンドでは，長鎖分岐高分子の添 加により伸長粘度のひずみ硬化性が観測されるとともに第一 法線応力差も大きくなる ${ }^{31)}$. すなわち, 本実験結果とは異な る特徵を示す。また，一般的な非相溶系ポリマーブレンドで は, せん断速度の増加とともに界面張力の影響で第一法線応 力差が増大することが知られている ${ }^{32}$. しかしながら, 本ブ レンド系の場合, 特に高せん断速度領域では第一法線応力差, せん断応力ともにわずかながらではあるが低下する傾向にあ ることが判明した。

\section{4. 結 論}

直鎖状のPP に対して長鎖分岐が存在する LDPE を混合す ると伸長粘度のひずみ硬化性を付与できることがこれまでに 報告されてきた。 また，このブレンドはコストパフォーマン スに優れることから工業的な応用が広く進んでいた。しかし ながら, 長鎖分岐高分子が分散相となる他の系で同様の現象 が示されたことはなかった。 そこで本研究では, LLDPEが 連続相, LCB-PPが分散相となった相分離系ポリオレフィン ブレンドの伸長およびせん断流動場でのレオロジー特性を検 討した。 その結果, LLDPE にLCB-PPをブレンドすること で伸長粘度のひずみ硬化性を付与できることが判明した。ま た, せん断流動場におけるせん断応力ゃ第一法線応力差には 大きな変化が生じないことを明らかにした。

LLDPE の伸長流動特性を改質しようとする場合，一般的 にはLDPEを混合する。そのため本研究で取り扱った系は実 用的には利用価值がそしいかもしれない。しかしながら，伸 長粘度のひずみ硬化性を付与する普遍的な方法として, 非相 溶な長鎖分岐高分子のブレンドが有効であることを示す結果 として今後の研究開発の参考になると期待している.

\section{REFERENCES}

1) Takahashi M, Masuda T, Onogi S, Nihon Reoroji Gakkaishi (J Soc Rheol Jpn), 11, 13 (1983).

2) Koyama K, Nihon Reoroji Gakkaishi (J Soc Rheol Jpn), 19, 174 (1991).

3) Shinohara M, Nihon Reoroji Gakkaishi (J Soc Rheol Jpn), 19, 118 (1991).

4) Yamaguchi M, "Material Strength in Molten State for Foam" in "Foam Extrusion: Principles and Practice", 2nd ed, (2014), Chap.4, Eds. Lee ST, Park CB, CRC Press, New York.

5) Münstedt H, Schwarzl FR, "Flow and Deformation of Polymeric Materials” (2014) Springer, Berlin.

6) Wingstrand SL, van Drongelen M, Mortensen K, Graham RS, Huang Q, Hassager O, Macromolecules, 50, 1134 (2017).

7) Yamaguchi M, Miyata H, Polym J, 32, 164 (2000).

8) Yamaguchi M, J Polym Sci B Polym Phys Ed, 39, 228 (2001).

9) Yamaguchi M, Suzuki K, J Polym Sci B Polym Phys Ed, 39, 2159 (2001).

10) Yokohara T, Nobukawa S, Yamaguchi M, J Rheology, 55, 1205 (2011).

11) Yamaguchi M, Fukuda K, Yokohara T, Mohd Amran BMA, Nobukawa S, Macromol Mater Eng, 297, 654 (2012).

12) Yamaguchi M, Yokohara T, Mohd Amran BMA, Nihon Reoroji Gakkaishi (J Soc Rheol Jpn), 41, 129 (2013).

13) Ogura K, Takahashi M, Nihon Reoroji Gakkaishi (J Soc Rheol Jpn), 28, 99 (2000).

14) Yamaguchi M, Takahashi M, Polymer, 42, 8663 (2001).

15) Siriprumpoonthum M, Nobukawa S, Satoh Y, Sasaki H, Yamaguchi M, J. Rheology, 58, 449 (2014).

16) Wagner MH, Kheirandish S, Yamaguchi M, Rheol Acta, 44, 198 (2004).

17) Mieda N, Yamaguchi M, J Non-Newtonian Fluid Mech, 166, 231 (2011).

18) Shiromoto S, Miyazawa $T$, Koyama K, Nihon Reoroji Gakkaishi (J Soc Rheol Jpn), 31, 321 (2003).

19) Fujii Y, Nishikawa R, Phulkerd P. Yamaguchi M, J Rheology, 63, 11 (2019).

20) Otsuki Y, Fujii Y, Sasaki H, Phulkerd P, Yamaguchi M, Polym J, in press, doi.org/10.1038/s41428-019-0286-0.

21) Batchelor GK, J Fluid Mech, 46, 813 (1971).

22) Mewis J, Metzner AB, J Fluid Mech, 62, 593 (1974).

23) Laun HM, Colloid Polym Sci, 262, 257 (1984).

24) Münstedt H, "Rheological and Morphological Properties of Dispersed Polymeric Materials” (2006) Hanser, Munich.

25) Yamaguchi M, Wagner MH, Polymer, 47, 3629 (2006).

26) Yamaguchi M, Miyata H, Nitta K, J Appl Polym Sci, 62, 87 (1996).

27) Yamaguchi M, Nitta K, Miyata H, Masuda T, J Appl Polym Sci, 63, 467 (1997).

28) Yamaguchi M, Miyata H, Macromolecules, 32, 5911 (1999).

29) Osaki K, Murai A, Bessho N, Kim BS, Nihon Reoroji Gakkaishi (J Soc Rheol Jpn), 4, 166 (1976).

30) Seemork J, T. Sako, B. M. A. Mohd Amran, M. Yamaguchi, $J$ Rheology, 61, 1 (2017).

31) Yamaguchi M, Abe S, J Appl Polym Sci, 74, 3153 (1999).

32) Doi M, Ohta T, J Chem Phys, 95, 1242 (1991). 